\title{
Comparative Magma/Xenolith Relationships in Some Volcanic and Plutonic Rocks From the French Massif Central
}

\author{
A Correction \\ R.C. Maury ${ }^{1}$, J. Didier ${ }^{2}$, and J. Lameyre ${ }^{3}$ \\ ${ }^{1}$ Laboratoire de Pétrologie, U.B.O., F-29283 Brest Cedex, France \\ ${ }^{2}$ Département de Géologie - Minéralogie, Laboratoire associé au CNRS, "Chronologie des terrains cristallins et Volcanologie", 5, \\ rue Kessler, F-63068 Clermont-Ferrand Cedex, France \\ 3 Laboratoire de Pétrologie, E.R.A. 381 "Géologie des granitoïdes", T.26.16.3E, 4, Place Jussieu, F-75230 Paris Cedex 05, France
}

In the paper intitled "Comparative Magma/Xenolith Relationships in Some Volcanic and Plutonic Rocks From the French Massif Central" (Contrib. Mineral. Petrol. 66, 401-408, 1978), the amount of "An" shown in Fig. $5 \mathrm{~A}$ and B indicates the relative proportions of anorthite in normative plagioclase. By contrast, the relative amount of "An" in Fig. 3 indicates
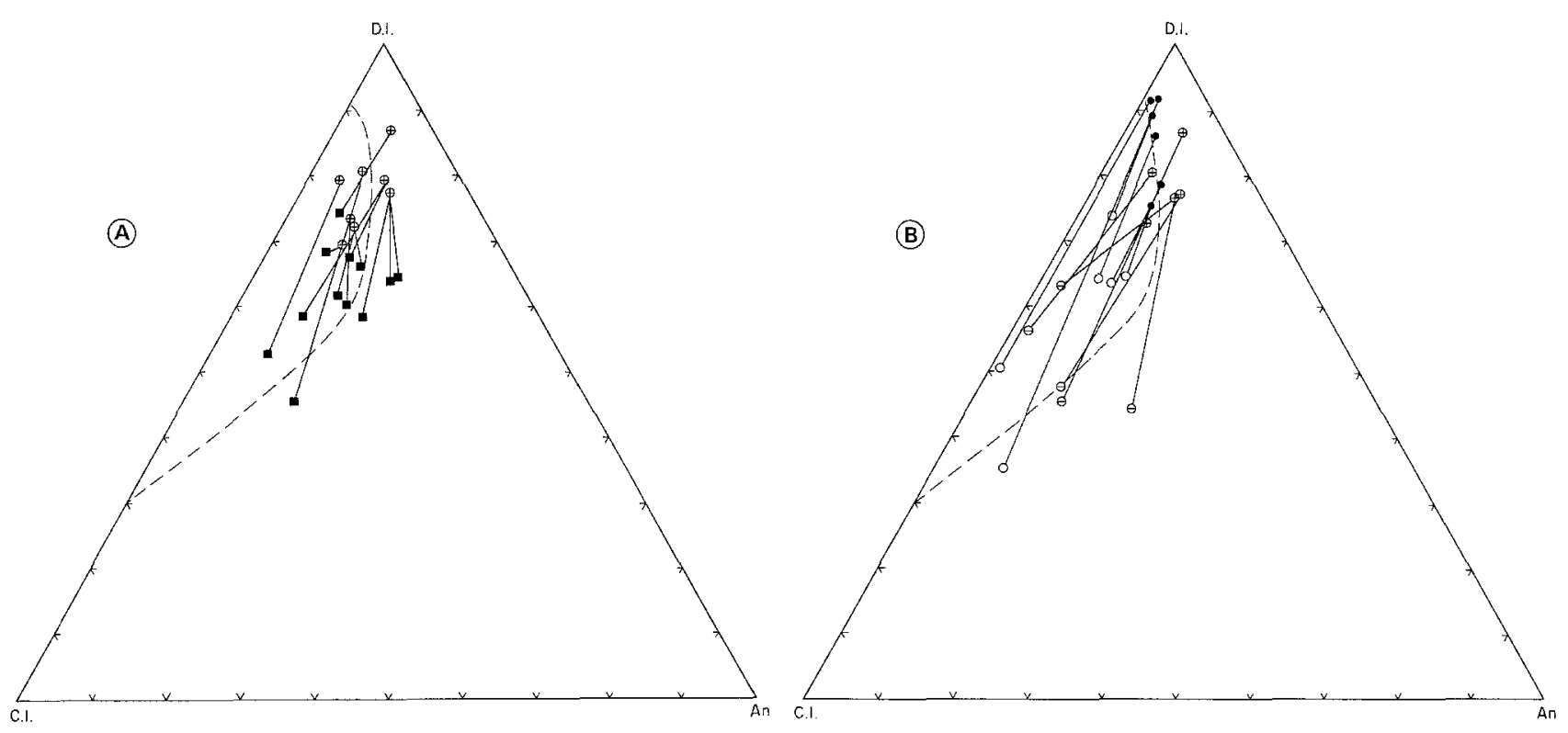

the proportions of normative anorthite in the whole rocks. The two figures were not directly comparable. The new figures presented here (Fig. 5A and B) allow one to make a direct comparison with Fig. 3, p. 404 of the former paper. We thank H. De La Roche for pointing out this discrepancy.

\section{Received January 18, 1979 ; Accepted February 5, 1979}

Fig. 5 A and B 